\title{
Microstructure and Mechanical Properties of Laser Repaired TC4 Titanium Alloy
}

\author{
Zhao Zhuang ${ }^{1}, \quad$ Chen Jing ${ }^{1}, \quad$ Tan Hua ${ }^{1}, \quad$ Zhao Xiaolin ${ }^{2}, \quad$ Huang Weidong ${ }^{1}$ \\ ${ }^{1}$ Northwestern Polytechnical University, State Key Laboratory of Solidification Processing, Xi'an 710072, China; ${ }^{2}$ AVIC Xi'an Aero-Engine \\ (Group) LTD, Xi'an 710021, China
}

\begin{abstract}
Laser Additive Manufacturing (LAM) was employed to fabricate repaired specimens with wrought TC4 as the substrate and TC4 powders with low oxygen $(\mathrm{O} \leq 0.13 \mathrm{wt} \%)$ as the cladding materials. The microstructure and mechanical properties of TC4 specimens fabricated by LAM and wrought billet were investigated comparatively. The results show that the macrostructure of the laser repaired specimen can be divided into three domains, including wrought substrate zone (SZ), heat affected zone (HAZ) and laser deposited zone (LDZ). The LDZ microhardness is equal to that of the SZ basically. And the HAZ microhardness is higher than that of both the LDZ and SZ slightly. The results of room temperature tensile test show that the strength and ductility of the wrought specimen are slightly higher than that of the laser repaired specimens. Meanwhile, the strength of the laser repaired specimen with repair ratio of $40 \%$ (i.e. area fraction of the $\mathrm{LDZ}$ on the transverse section of tensile specimen within gauge part is $40 \%$ )is slightly lower than that of $50 \%$ repaired specimen, but the ductility is higher than the latter. Therefore it is favorable to match the strength and ductility of the wrought substrate with the LDZ with low oxygen TC4 powders as the cladding materials, so as to improve the comprehensive properties of laser repaired TC4 titanium alloy. The wrought specimen tensile fracture presents a typical ductile characteristic, and the repaired specimen shows a complex fractograph. From the LDZ to the SZ, the tensile fracture presents a successive transformation from cleavage step to dimple fracture. It can be seen that there is a good corresponding relationship between the fracture morphology and the microstructure of the tensile specimens.
\end{abstract}

Key words: laser repair; titanium alloy; microstructure; mechanical properties; fracture mechanism

TC4 is a kind of $\alpha+\beta$ titanium alloys with medium strength, containing $6 \mathrm{wt} \% \mathrm{Al}$ which is a stable element of $\alpha$ phase, and $4 \mathrm{wt} \% \mathrm{~V}$ which is a $\beta$ stable element. It is widely employed to fabricate engine fans, compressor disks, blades and heavy load components due to its excellent comprehensive service performances in the field of aeronautic and astronautic industries $^{[1,2]}$. Mis-machining damage occurring during the productive process and foreign object damage encountered in the service process become the problems ought to be faced with the increasing of application amount of titanium alloy components of new aircraft. It is urgent to develop new repair techniques to reverse huge losses both on economy and delivery time resulted from the damage of high value components.

Traditional repair techniques, such as brazing, argon arc welding, thermal spraying and electric discharge machining, are usually used to repair the surface defects or the defects with simple shapes. In addition, the heat-input and heat affected zone in the damaged components during welding such as TIG welding is large, which may cause a large residual stress and distortion and low mechanical properties for the final repaired components ${ }^{[3]}$. In recent years, based on the Laser Additive Manufacturing (LAM) process, an advanced solid free form fabrication, a new advanced repair technique, laser repair (LR), has been developed. Since LAM has been employed to fabricate fully dense and three

Received date: July 15,2016

Foundation item: National Natural Science Foundation of China (51475380); Research Fund of the State Key Laboratory of Solidification Processing (NWPU), China (99-QP-2014)

Corresponding author: Chen Jing, Ph. D., Professor, State Key Laboratory of Solidification Processing, Northwestern Polytechnical University, Xi'an 710072, P. R. China, E-mail: phd2003cjj@nwpu.edu.cn 
dimensions components with high performance and complex structure, if we set the mis-machining or damaged components as the substrate, and build up worn sections of metal components, the geometrical properties and mechanical properties of the mis-machined or damaged components could be restored. Compared with the traditional repairing techniques, LR has the advantages of high automation, controllable heat input introduced into the damaged components, metallurgical bonding between the repaired zone and the body part, and reasonable repairing $\operatorname{cost}^{[4-7]}$. It has been gradually applied to repair the mis-machining or damaged components. In Germany, the Fraunhofer Institute of Laser Technology has repaired the damaged blades of titanium blisks with LR. They found that the laser deposited zone (LDZ) microstructure was fully dense with no oxidation since the process was performed in a sealed chamber filled with pure argon gas. In addition, the heat-input in the damaged components during the LR process was less, which caused less distortion compared with TIG welding. Finally, repaired parts with excellent performance could be obtained ${ }^{[8]}$. In China, Weidong Huang et $\mathrm{al}^{[3,7]}$, State Key Laboratory of Solidification Processing of Northwestern Polytechnical University, had launched the LAM and LR research. Results show that there is a dense metallurgical bond between the LDZ and the substrate. The LDZ microstructure is composed of primary columnar $\beta$ grains within which exist $\alpha+\beta$ Widmannstatten structures. The results of hardness and room temperature tensile test show that the LDZ hardness is higher than that of the wrought matrix; meanwhile, the plasticity of the LAMed specimens is lower than that of the wrought specimens. Therefore, the LDZ and the wrought matrix can be treated as a combination of "strong+weak" ${ }^{,[9,10]}$. But, currently, about the relationship between the failure behavior and the microstructure of LRed TC4 titanium alloy in tensile test is rarely reported.

In the present paper LAM has been employed to fabricate repaired specimens with wrought TC4 as the substrate and TC4 powders with low oxygen $(\mathrm{O} \leq 0.13 \mathrm{wt} \%)$ as the cladding materials. The microstructure and mechanical properties of TC4 specimens fabricated by LAM and wrought billet were investigated comparatively.

\section{Experiment}

The experiments were performed on a LAM system typed LSF-IIIB, established by State Key Laboratory of Solidification Processing, which consisted of a $4 \mathrm{~kW}$ continuous wave $\mathrm{CO}_{2}$ laser, a five-axis numerical control working table, a powder feeder with a coaxial nozzle and a chamber filled with pure argon gas, etc. The substrate was wrought TC4 alloy. The wrought substrate is composed of duplex microstructure as shown in Fig.1. The TC4 powders prepared by plasma rotating electrode with the size of -100 mesh were employed as the cladding materials. The chemical composition of the substrate

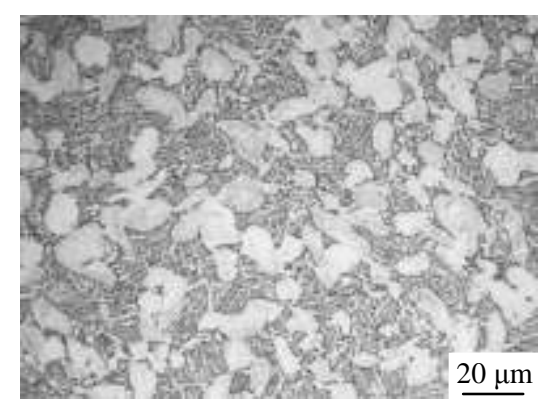

Fig.1 Microstructure of the TC4 wrought substrate

and the cladding powders are listed in Table 1 . The powders were dried in a vacuum oven for $2 \mathrm{~h}$ at $(120 \pm 10){ }^{\circ} \mathrm{C}$. The processing parameters of LR are shown in Table 2.

Before the LR experiment, the wrought billet of TC4 alloy was machined to obtain specimens with a prefabricated surface defect, as shown in Fig.2a (solid line shows the specimen with surface defect, dot line shows the LRed tensile specimen). Then, the surface to be repaired was polished by abrasive papers and cleaned by acetone. The LAM technique with mutually perpendicular scanning path was employed to accomplish the LRed specimens and the height of LDZ was about $5 \mathrm{~mm}$. The LRed specimens are shown in Fig.2b. The LRed TC4 alloy specimens were machined into the standard tensile specimens and the repair ratio was set to $40 \%$ and $50 \%$. Fig. 3 shows the geometric figure of a tensile bar. The tensile properties were tested on a German electronic tensile testing machine ZWICK according to GB/T228-2010 specification. After tensile failure, the $40 \%$ repaired specimen was sectioned and got a cross-section at the farthest position from the fracture within the gauge length for microstructural observation. The microstructure of the LRed specimens was revealed using the etchant of $10 \mathrm{~mL} \mathrm{HF}+30 \mathrm{~mL} \mathrm{HNO}_{3}+50 \mathrm{~mL}$ $\mathrm{H}_{2} \mathrm{O}$, and examined by an OLYMPUSGX71 optical microscope. The microhardness of the LRed specimens from the LDZ to the substrate zone (SZ) was further tested by a Duramin-A300 microhardness tester with the load of $0.5 \mathrm{~kg}$. The tensile fracture of the wrought and LRed specimens was observed by a TESCAN VEGA II LMH scanning electron microscope.

Table 1 Chemical composition of the TC4 powders and the wrought substrate (wt\%)

\begin{tabular}{lcccccccc}
\hline & $\mathrm{Al}$ & $\mathrm{V}$ & $\mathrm{Fe}$ & $\mathrm{O}$ & $\mathrm{C}$ & $\mathrm{N}$ & $\mathrm{H}$ & $\mathrm{Bal}$. \\
\hline Powders & 6.10 & 4.20 & 0.12 & 0.08 & 0.01 & 0.015 & 0.009 & $\mathrm{Ti}$ \\
Substrate & 6.42 & 3.88 & 0.20 & 0.16 & 0.02 & 0.01 & 0.010 & $\mathrm{Ti}$ \\
\hline
\end{tabular}

Table 2 Experiment parameters of the LR process

\begin{tabular}{cccccc}
\hline $\begin{array}{c}\text { Laser } \\
\text { powder/W }\end{array}$ & $\begin{array}{c}\text { Scanning } \\
\text { velocity/ } \\
\mathrm{mm} \cdot \mathrm{s}^{-1}\end{array}$ & $\begin{array}{c}\text { Laser spot } \\
\text { diameter/ } \\
\mathrm{mm}\end{array}$ & $\begin{array}{c}\text { Powder } \\
\text { feeding rate/ } \\
\mathrm{g} \cdot \mathrm{min}^{-1}\end{array}$ & $\begin{array}{c}\triangle Z / \\
\mathrm{mm}\end{array}$ & $\begin{array}{c}\text { Overlap } \\
\text { rate/\% }\end{array}$ \\
\hline 2200 & 10 & 2 & 5 & 0.3 & 40,50 \\
\hline
\end{tabular}



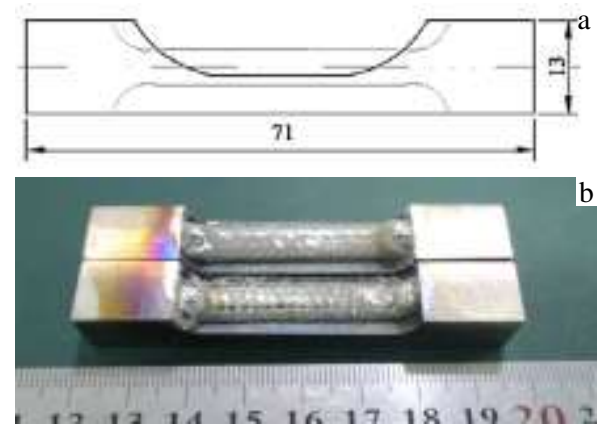

Fig.2 LRed specimens of TC4 alloy: (a) sketch of the specimen with a prefabricated surface defect and (b) specimens after laser repair

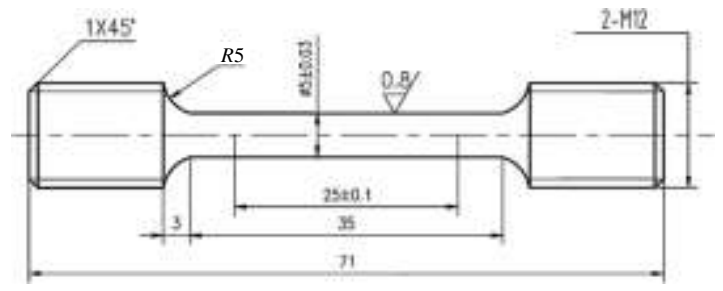

Fig.3 Geometric figure of the standard tensile testing bar

\section{Results and Discussion}

\subsection{Microstructure of LRed TC4 titanium alloy}

Macrostructure of the LRed specimen of TC4 alloy is shown in Fig.4. In terms of different microstructural characteristic, the LRed specimen can be divided into three zones: the LDZ, heat affected zone (HAZ) and SZ. The depth of HAZ is about $0.8 \mathrm{~mm}$.

The LDZ is composed of prior columnar $\beta$ grains which grow epitaxially across several deposition layers (Fig.5a). The main axes of columnar $\beta$ grains are perpendicular to the laser beam scanning direction. The microstructure is obviously different in different positions of the LDZ. On the top of the LDZ (Fig.5d), the original $\beta$ grain boundaries are blurred, and no significant $\alpha$ phase is observed on the grain boundaries. While the intracrystalline $\alpha$ phase presents fine acicular structure. Meanwhile, at the bottom of the LDZ (Fig.5b), the $\alpha$ phase presents an appearance of lath and the aspect ratio is significantly less than that of the top. At the same time, the grain boundaries are distinct and continuous, where $\alpha$ laths with a thickness of about $2 \mu \mathrm{m}$ distribute. The middle of the LDZ microstructure shows a transformation from the bottom to the top (Fig.5c). So, on the whole, the LDZ experiences a continuous microstructural transition from the bottom with the complex microstructure of blend of basket weave and Widmannstatten structure to the top with the acicular Widmannstatten structure.

Fig.6 shows the HAZ microstructure. Overall, the HAZ experiences a continuous microstructural transition from the

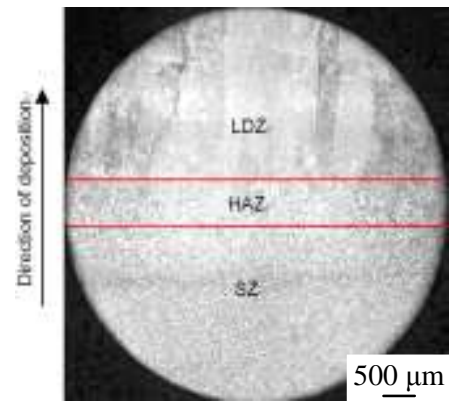

Fig.4 Macrostructure of the LRed TC4 alloy specimen

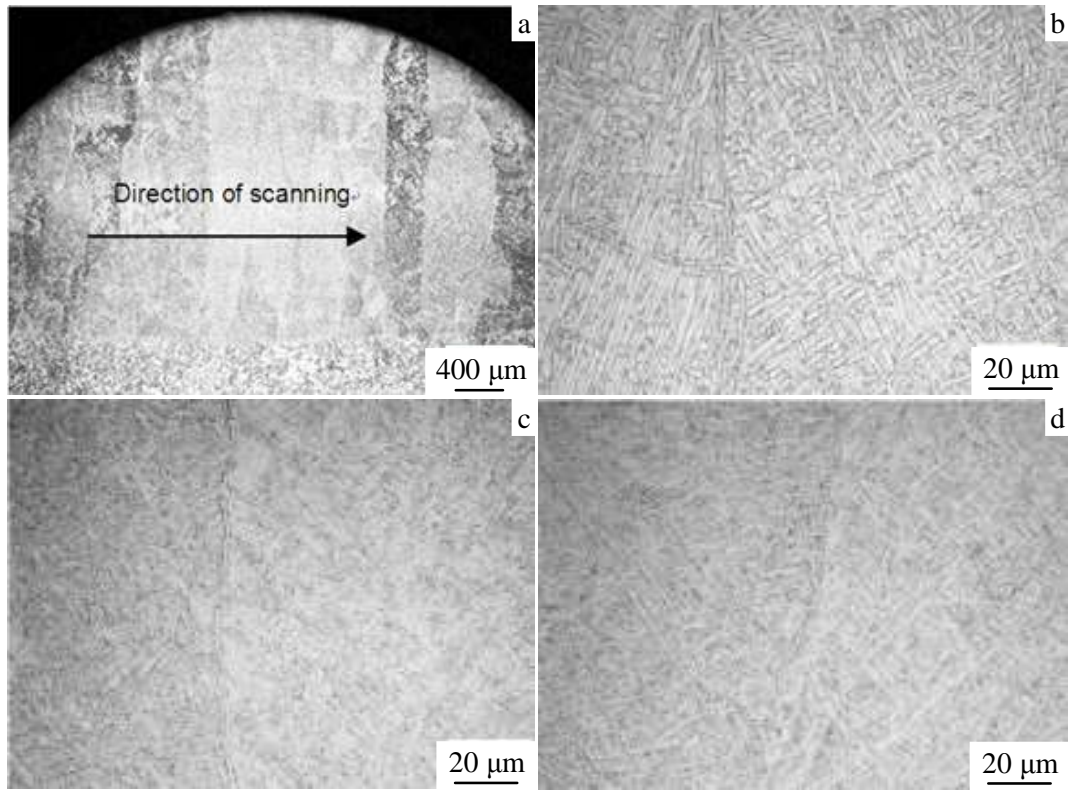

Fig.5 LDZ microstructures of different positions for the LRed TC4 alloy: (a) macrostructure, (b) at the bottom, (c) in the middle, and (d) on the top 

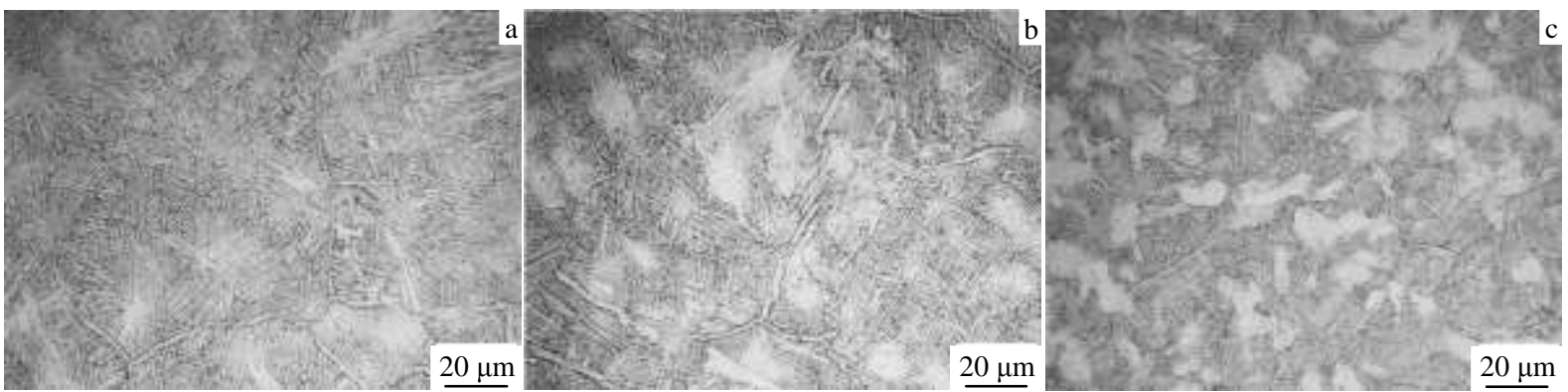

Fig.6 HAZ microstructures of the LRed TC4 alloy specimen: (a) close to the interface, (b) middle, and (c) close to the substrate

substrate with the duplex microstructure to the LDZ with the Widmannstatten structure. During the LR process, in the substrate close to the LDZ undergoing the reciprocating reheat cycle, the primary $\alpha$ phase dissolve into the $\beta$ phase gradually with the increase of temperature and the fine secondary $\alpha$ phase precipitate from the $\beta$ phase with the decrease of temperature. The $\alpha$ phase on the grain boundaries interconnected into the network. The closer to the LDZ, the larger size the equiaxed grains are in the HAZ. In addition, it can be seen that the secondary $\alpha$ phase precipitated from the $\beta$ phase are coarser in the HAZ from the area close to the SZ to the area near the LDZ.

\subsection{Microhardness of LRed TC4 titanium alloy}

The microhardness distribution of the LRed TC4 alloy is shown in Fig.7. It can be seen that the microhardness in the HAZ achieves a mild peak, with the microhardness (HV) value of about $(3610 \pm 30) \mathrm{MPa}$. The SZ presents a similar micro-hardness value to the LDZ of about $(3430 \pm 50) \mathrm{MPa}$. It is attributed to the formation of fine secondary $\alpha$ phase in the HAZ, which leads to the increase of the microhardness.

\subsection{Room temperature tensile properties}

The room temperature tensile properties of wrought specimens and LRed specimens with different repair ratios are shown in Table 3. It can be seen that the strengths and ductility of the wrought specimen are slightly higher than those of the LRed specimens. In this experiment, the oxygen content of TC4 alloy powder is $0.08 \mathrm{wt} \%$ and the LR process is performed in a chamber filled with pure argon gas $(\mathrm{O} \leq 50$

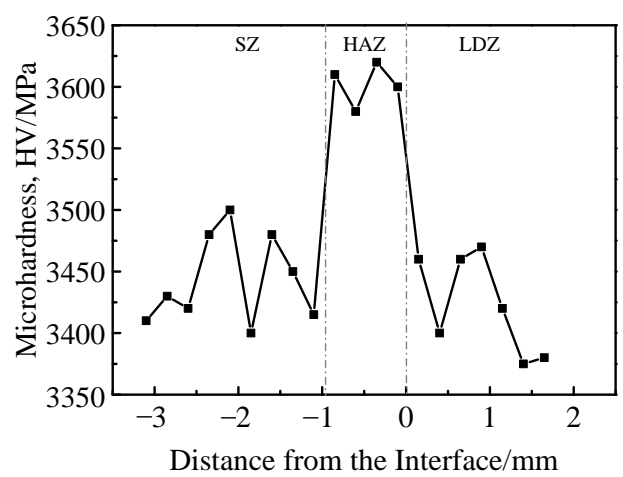

Fig.7 Microhardness of the LRed TC4 alloy specimen $\mu \mathrm{L} / \mathrm{L})$. The oxygen content of $\mathrm{LDZ}$ is less than $0.09 \mathrm{wt} \%$ actually, which is much lower than the oxygen content of wrought specimen $(0.16 \mathrm{wt} \%)$. As we know, the strength of titanium alloy would increase by $70 \mathrm{MPa}$ with the oxygen content increasing by each $0.01 \mathrm{wt} \%$. Thus, the tensile strength of wrought specimen should be much higher than that of the LRed specimen. On the other hand, the microstructure of the tensile specimen also affects the mechanical properties. As discussed above, the microstructure of the wrought specimen is duplex while that of the LAMed specimen is Widmannstatten structure, and the former has a lower strength than the latter ${ }^{[11]}$. Thus, the combined effect of two factors mentioned above leads to the slightly lower strength and ductility of the LRed TC4 specimens than those of the wrought specimen. Compared 1\# LRed specimen (40\% repair ratio) with $2 \#$ LRed specimen (50\% repair ratio), it can be seen that the ultimate and yield strength of 2\# LRed specimen are slightly higher than those of $1 \#$ LRed specimen, while the ductility is lower. It is further evidenced that the strength of LDZ with Widmannstatten structure is higher than that of the wrought substrate. Thus, it is favorite to match the strength and ductility of the substrate with the LDZ as employing low oxygen TC4 powders as the cladding material, so as to improve the comprehensive properties of the repaired specimens.

\subsection{Tensile fracture}

The tensile fracture morphology of wrought and LRed TC4 alloy were further observed. Fig. 8 shows the contrast between macro-fractographies and macrostructure. It can be found that the tensile fracture of the three specimens show a cup-shape with obvious plastic deformation, shear lip is obvious and the ratio of fiber area (the blue region of the envelope) is large. The tensile fracture of LRed specimens and their macrostructure show a good corresponding relation. Further observed in Fig.9, it is found that those high magnification SEM fractographies are corresponding to the LDZ, HAZ and

\begin{tabular}{ccccc} 
Table 3 & Room temperature tensile properties of TC4 alloy \\
\hline Specimens & $\sigma_{\mathrm{b}} / \mathrm{MPa}$ & $\sigma_{0.2} / \mathrm{MPa}$ & $\delta / \%$ & $\Psi / \%$ \\
\hline Wrought & 1032 & 970 & 17.0 & 49.0 \\
1\# LRed & 1005 & 927 & 14.3 & 34.5 \\
2\# LRed & 1013 & 953 & 12.5 & 26.0 \\
\hline
\end{tabular}




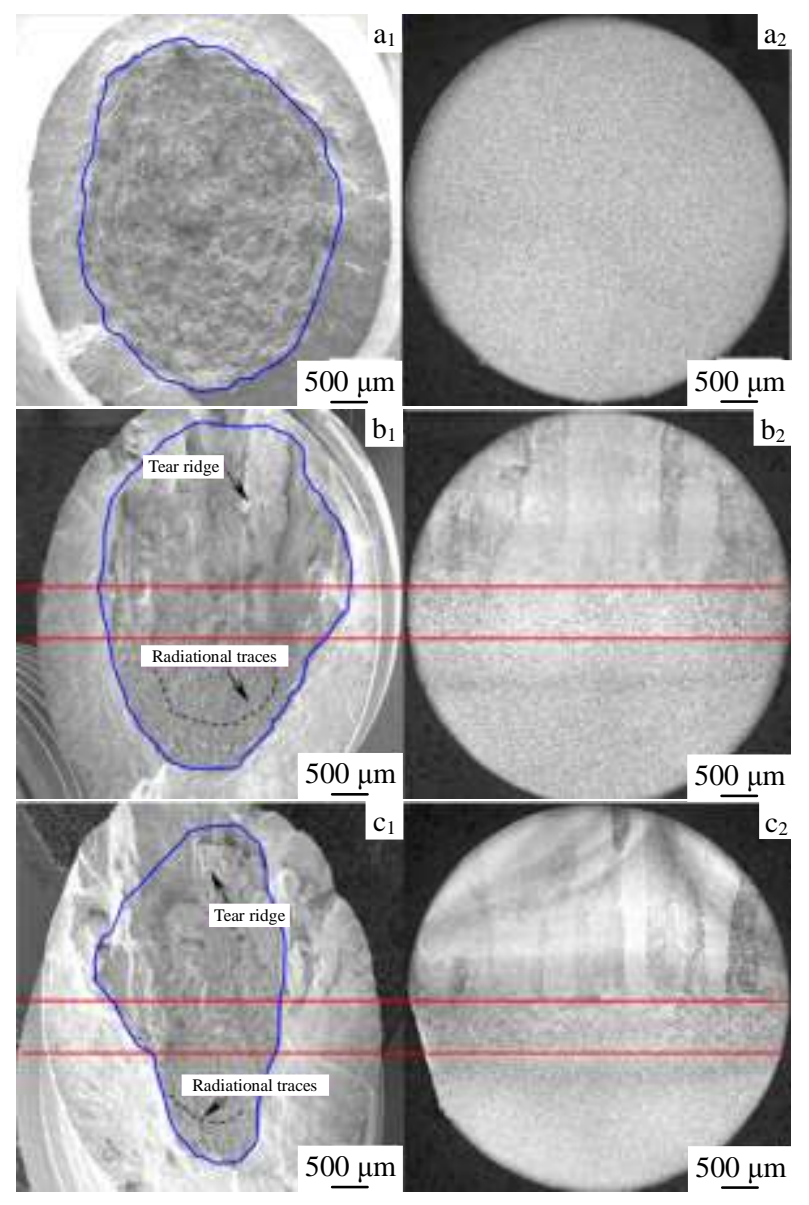

Fig.8 Contrast with tensile fractures and macrostructure: (a1, a2) wrought specimen, (b1, b2) 1\# specimen, and (c1, c2) 2\# specimen

SZ with the significantly different fracture characteristics. Fig.9a gives the micro-fractograph of the LDZ, which shows a cleavage fracture with considerable cleavage steps and we can see some small and shallow dimples (Fig.9b). High magnification SEM images of the HAZ fractograph are also shown in Fig.9c and 9d. It can be seen that the micro-fractograph of the HAZ presents a quasi-cleavage fracture with a cleavage and dimple mixed characteristic. The macro-fractography of the substrate shows a stuffed goose shape with a great quantity of deep dimples dispersing on the fracture surface. So, on the whole, when experienced the static tensile load for LRed specimens, it shows a mixed fracture transformation from cleavage to dimple continuously which is corresponding to the continuous microstructural transition from the epitaxial coarse columnar $\beta$ with fine Widmanstatten $\alpha+\beta$ in the LDZ to the duplex microstructure in the substrate.

Further analyzing the macro-fractographs of LRed specimens (Fig.8b1, 8b2, 8c1, 8c2), it can be seen that some regions present the tear ridges which form from the HAZ to the top of the LDZ. In addition, the substrate also presents the radiational traces which left behind during the crack

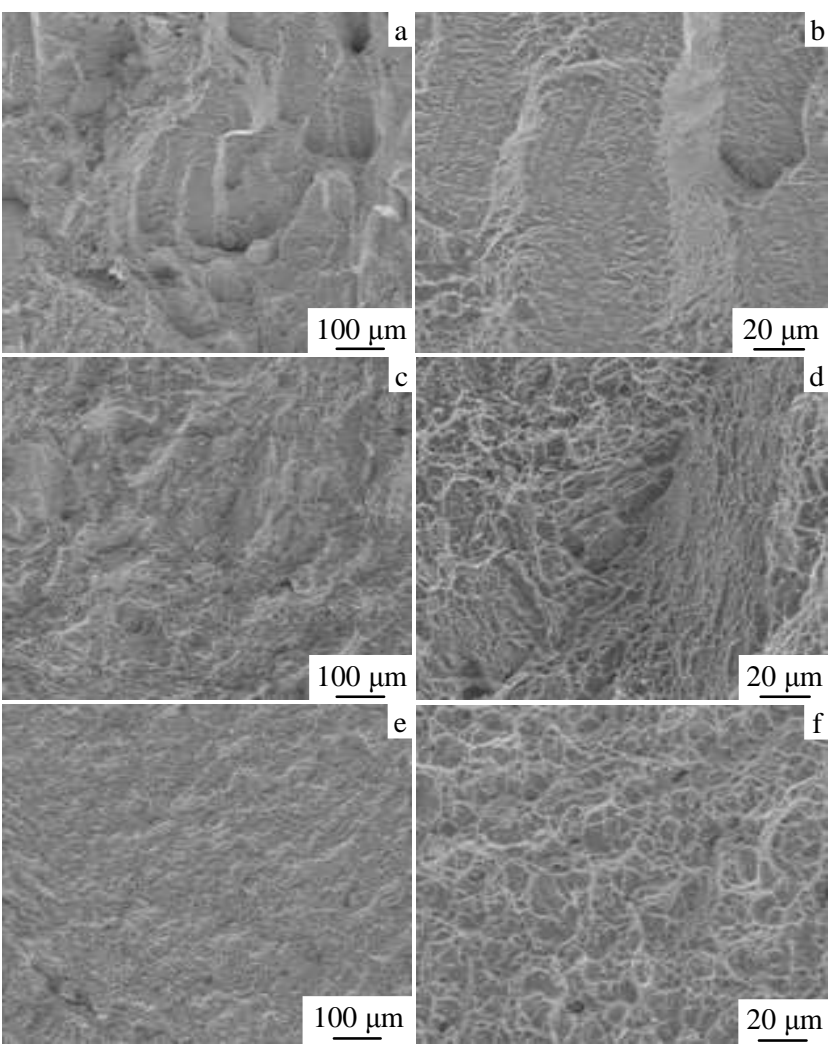

Fig.9 Fractographys of LRed TC4 alloy: (a, b) LDZ, (c, d) HAZ, and $(e, f) S Z$

propagation from the HAZ to the substrate. So it can be inferred that the cracks initiate in the HAZ firstly, and then extend to the LDZ and the substrate simultaneously. As mentioned above, the microhardness in the HAZ is slightly higher than that of the substrate and LDZ, which cause the HAZ break firstly under the tensile process and become the source of cracks.

Compared with the macro-fractographs of LRed and wrought specimens, it is found that the fiber area of LRed specimens presents an irregular oval shape but the wrought specimen shows an approximate circularity. And the fiber area of LDZ is larger than that of SZ of the LRed specimen. It means that both the size and the shape of the fiber area significantly change when the LDZ takes part in the tensile specimen. Since the crack expansion of cleavage stage in the LDZ is faster than that of dimple in the substrate, the geometric morphology of the fiber area mentioned above is formed. Further analyzing the fracture of the LRed specimens, it can be seen that the shear lip of the LDZ is small and that of the substrate is large. It is also attributed to that crack propagation is fast in the LDZ, plastic deformation is limited to a small area at the front of the crack, only when the plastic deformation is near the surface of the specimen, forming the shear lip under the shear stress. The area of the fiber area can be used to assess plastic property of tensile specimens. The 
more the fiber area occupied, the better the ductility was ${ }^{[12]}$. Here, the fraction of the fiber area in the total area of the fracture is named as $R$. Thus, the larger the $R$ is, the better the ductility is for the metal materials. In this experiment, $R$ of the wrought specimen $\left(R_{\mathrm{w}}\right)$ is 0.565 , that of 1 \# LRed specimen $\left(R_{1}\right)$ and 2\# LRed specimen $\left(R_{2}\right)$ are 0.545 and 0.432 , respectively. So, there are $R_{\mathrm{w}}>R_{1}>R_{2}$. Comparing $R$ value of the LRed specimens with different repair ratios and wrought specimen, it can be noted that the repair ratio has a great effect on tensile properties.

\section{Conclusions}

1) The macrostructure of LRed TC4 titanium alloy can be divided into three zones: the LDZ, HAZ and SZ. And the LDZ presents a continuous microstructural transition. At the bottom of the LRed specimen there is a blend microstructure of basketweave structure and Widmannstatten structure while at the top there is an acicular Widmannstatten structure. The HAZ experiences a continuous microstructural transition from the wrought substrate with the duplex microstructure to the LDZ with the Widmannstatten structure.

2) Due to the fine secondary $\alpha$-phase the HAZ microhardness is higher than both LDZ and SZ slightly.

3) The strength and ductility of the wrought specimen are slightly higher than those of the laser repaired specimens. Meanwhile, the strength of $40 \%$ repaired specimen is slightly less than that of $50 \%$ repaired specimen, but the ductility is higher than that of the latter.

4) The fracture morphology of the wrought TC4 specimen presents a typical ductile fracture feature with dimple characteristic. While the LRed TC4 specimen shows a complex feature with a continuous transformation from a cleavage fracture in the LDZ to a dimple fracture in the SZ. In addition, when the LDZ takes part in the tensile specimen, the size and shape of the fiber area of the LRed specimen change obviously compared with the wrought specimen.

\section{References}

1 Brandl E, Baufeld B, Leyens C et al. Physics Procedia[J], 2010(5): 495

2 Luo Yong, Ge Shirong. Tribology International[J], 2009, 42(9): 1373

3 Huang Weidong, Lin Xin, Chen Jing et al. Laser Solid Forming Technology[M]. Xi'an: NPU Press, 2007: 10 (in Chinese)

4 Berminham M J, Kent D, Zhan H et al. Acta Materialia[J], 2015, 91: 289

5 Lin Xin, Cao Yongqing, Wu Xiaoyu et al. Materials Science and Engineering $A[\mathrm{~J}], 2012$, 553: 80

6 Zhu Yanyan, Li Jia, Wang Huaming et al. Materials Science and Engineering A[J], 2014, 607: 427

7 Huang Weidong, Lin Xin. Materials China[J], 2010, 29(6): 12 (in Chinese)

8 Http://www.ilt.fraunhofer.de/de/institutsprofil.html

9 Zhang Shuangyin, Lin Xin, Chen Jing et al. Chinese Optics Letters[J], 2009, 6(7): 1

10 Xue Lei, Chen Jing, Lin Xin et al. Rare Metal Materials and Engineering [J], 2007, 36(6): 989 (in Chinese)

11 Chen Jing, Zhang Shuangyin, Xue Lei et al. Rare Metal Materials and Engineering[J], 2007, 36(3): 475 (in Chinese)

12 Zhong Qunpeng, Zhao Zihua. Fracture Analysis[M]. Beijing: High Education Press, 2006: 204 (in Chinese)

\title{
激光修复 TC4 钛合金显微组织与力学性能
}

\author{
赵 庄 ${ }^{1}$, 陈 静 $^{1}$, 谭 华 $^{1}$, 赵小林 ${ }^{2}$, 黄卫东 ${ }^{1}$ \\ (1. 西北工业大学 凝固技术国家重点实验室, 陕西西安 710072) \\ (2. 西安航空发动机(集团)有限公司, 陕西 西安 710021)
}

\begin{abstract}
摘 要：以低氧 TC4 粉末为熔覆材料, 采用激光修复技术制备了 TC4 钛合金面修复试样，对比研究了锻件和修复试样（沉积态）的显 微组织和力学性能。结果显示: 修复试样的组织宏观上分为锻件基材区、热影响区和激光沉积区, 3 个区域中热影响区的显微硬度最高, 沉积区和锻件基材的显微硬度相当。锻件试样的强度及塑性均略高于修复试样，同时发现 $40 \%$ 修复试样（即拉伸试样承受载荷部位横截 面上沉积区所占的面积分数为 $40 \%$ ）的强度略低于 50\%修复试样, 塑性则高于后者。表明采用低氧 TC4 粉末为熔覆材料时, 有利于修 复试样沉积区和基材区强度和塑性的匹配, 从而提高修复试样的综合性能。对拉伸断口进行扫描电镜观察发现, 锻件试样拉伸失效后断 口呈现出典型的韧性断裂特征, 而修复试样的断口则表现复杂, 从沉积区到锻件基材区呈现出解理台阶到韧窝的连续变化特征, 同时断 口形貌与显微组织呈现出很好的对应关系。
\end{abstract}

关键词：激光修复; 钛合金; 组织; 机械性能; 断裂机制 